\title{
Epidemiological and clinical characteristics of patients infected with enterovirus D68, France, July to December 2014
}

I Schuffenecker ${ }^{123}$, A Mirand ${ }^{345}$, L Josset ${ }^{12}$, C Henquell ${ }^{45}$, D Hecquet ${ }^{6}$, L Pilorgé ${ }^{7}$, J Petitjean-Lecherbonnier ${ }^{8}$, C Manoha ${ }^{9}$, J Legoff ${ }^{10}$, C Deback ${ }^{11}$, S Pillet ${ }^{12}$, Q Lepiller ${ }^{13}$, JM Mansuy ${ }^{14}$, S Marque-Juillet ${ }^{15}$, D Antona ${ }^{16}$, H Peigue-Lafeuille ${ }^{45}$, B Lina ${ }^{12}$

1. Centre National de Référence des Enterovirus et Parechovirus, Laboratoire de Virologie, Hospices Civils de Lyon, Lyon, France

2. Laboratoire Virpath, EA4610, Faculté de médecine Lyon Est, Université Claude Bernard Lyon 1, Lyon, France

3. These authors contributed equally to this work

4. CHU Clermont-Ferrand, Laboratoire de Virologie, Centre National de Référence des Enterovirus et Parechovirus - laboratoire associé, Clermont-Ferrand, France

5. Université d'Auvergne, EA4843 “Epidémiologie et pathogénie des infections à entérovirus”, Clermont-Ferrand, France

6. Laboratoire de Virologie, CHU Amiens, Amiens, France

7. Laboratoire de Virologie, CHRU de la Cavale Blanche, Brest, France

8. Laboratoire de Virologie, CHU Caen, Caen, France

9. Laboratoire de Virologie, CHU Dijon, Dijon, France

10. Laboratoire de Microbiologie, Hôpital Saint-Louis, APHP, Paris, France

11. Laboratoire de Virologie, Hôpital Paul Brousse, APHP, Villejuif, France

12. Laboratoire des agents infectieux et hygiène, CHU de Saint-Etienne, Saint-Etienne, France

13. Laboratoire de Virologie, Hôpitaux Universitaires de Strasbourg, Strasbourg, France

14. Laboratoire de Virologie, CHU Toulouse, Toulouse, France

15. Laboratoire de Microbiologie, CH Versailles, Versailles, France

16. Institut de Veille sanitaire, Département des Maladies Infectieuses, Saint-Maurice, France

Correspondence: Isabelle Schuffenecker (isabelle.schuffenecker@chu-lyon.fr)

Citation style for this article:

Schuffenecker I, Mirand A, Josset L, Henquell C, Hecquet D, Pilorgé L, Petitjean-Lecherbonnier J, Manoha C, Legoff J, Deback C, Pillet S, Lepiller Q, Mansuy JM, Marque-Juillet S, Antona D, Peigue-Lafeuille H, Lina B. Epidemiological and clinical characteristics of patients infected with enterovirus D68, France, July to December 2014. Euro Surveill. 2016;21(19):pii=30226. DOI: http://dx.doi.org/10.2807/1560-7917.ES.2016.21.19.30226

In 2014, the United States (US) experienced a nationwide outbreak of enterovirus D68 (EV-D68) infection with 1,152 cases reported mainly in hospitalised children with severe asthma or bronchiolitis. Following the US alert, 11 laboratories of the French enterovirus (EV) surveillance network participated in an EV-D68 survey. A total of 6,229 respiratory samples, collected from 1 July to 31 December 2014, were screened for EV-D68 resulting in 212 EV-D68-positive samples. These 212 samples corresponded to 200 EV-D68 cases. The overall EV-D68 positivity rates among respiratory samples were of $5 \%(184 / 3,645)$ and $1.1 \%(28 / 2,584)$ in hospitalised children and adults respectively. The maximum weekly EV-D68 positivity rates were of $16.1 \%$ for children ( $n=24 / 149$; week 43$)$ and $2.6 \%$ for adults $(n=3 / 115$; week 42). Of 173 children with EV-D68 infection alone, the main symptoms were asthma $(n=83$; $48.0 \%)$ and bronchiolitis $(n=37 ; 21.4 \%)$. One child developed acute flaccid paralysis (AFP) following EV-D68-associated pneumonia. Although there was no significant increase in severe respiratory tract infections reported to the French public health authorities, $10.7 \%(19 / 177)$ of the EV-D68 infected children and $14.3 \%(3 / 21)$ of the EV-D68 infected adults were hospitalised in intensive care units. Phylogenetic analysis of the viral protein 1 (VP1) sequences of 179 EV-D68 cases, revealed that 117 sequences (65.4\%), including that of the case of AFP, belonged to the B2 variant of clade B viruses. Continuous surveillance of EV-D68 infections is warranted and could benefit from existing influenza-like illness and EV surveillance networks.

\section{Introduction}

Enterovirus D68 (EV-D68) was first identified in the United States (US) in 1962 in four paediatric patients with acute respiratory infections (ARI) [1-11]. Until 2014, only sporadic cases of infection with this virus as well as small outbreaks (10 publications during 2006-2011) were reported in Asia, Europe and the US [1-11], with disease manifestations mainly ranging from mild respiratory symptoms to severe $A R I$ requiring intensive care and mechanical ventilation.

In 2014, the US experienced a nationwide outbreak of EV-D68 infection associated with an upsurge of severe respiratory cases admitted to emergency departments. Between mid-August and mid-December, 1,152 EV-D68 cases were reported by the Centers for Disease Control and Prevention (CDC) in 49 states, mainly in hospitalised children with severe asthma or bronchiolitis and occasionally in children with acute flaccid myelitis [12]. The overall disease burden was however, probably 
Distribution of enterovirus D68 cases by week and by age, France, July-December 2014 (n=209)

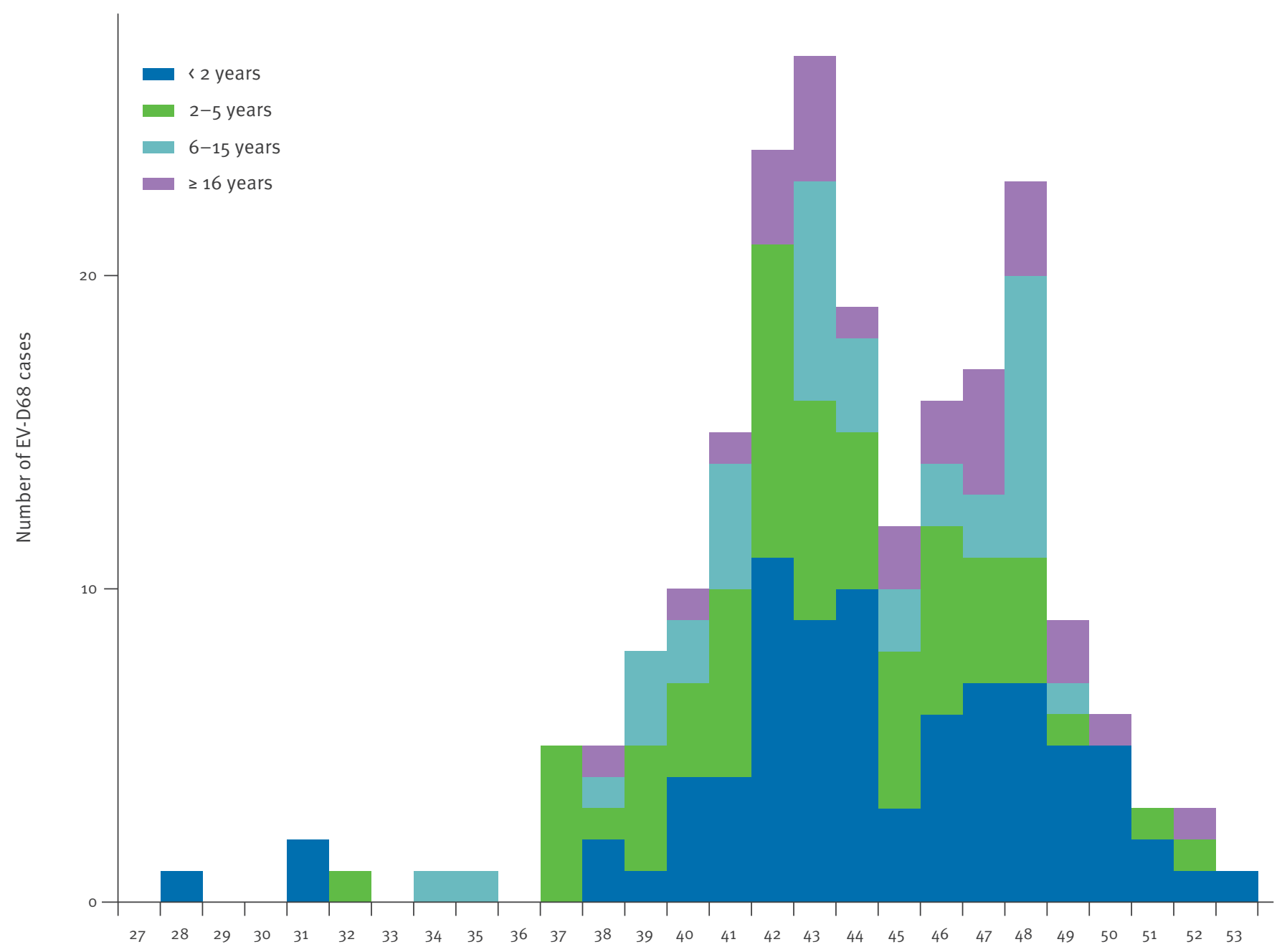

much higher [13,14]. During the autumn, European countries did not report a global increase in hospital admissions for severe respiratory infections or a significant upsurge of ARI [15]. However, reports from Norway and the Netherlands suggested that EV-D68 circulation might have increased $[16,17]$.

In France, enterovirus (EV) surveillance and molecular typing involve a network of hospital virology laboratories and focus mainly on EV neurological infections in hospitalised patients [18]. In hospitalised patients with respiratory infections, human rhinoviruses and enteroviruses (HRV/EV) infections have been more systematically investigated since early 2010 , due to the recent development of $\mathrm{HRV} / \mathrm{EV}$ and commercial multiplex reverse-transcription polymerase chain reaction (RT-PCR) assays, but they remain underdiagnosed. In addition, no routine typing of EV and HRV is performed, even in severe respiratory cases. In late September 2014, a French child developed severe acute flaccid paralysis (AFP) following EV-D68 pneumonia [19]. Taking all these factors into account, the National Institute of Public Health encouraged the French EV surveillance network to conduct a systematic analysis of respiratory samples collected from hospitalised patients to evaluate both the level of EV-D68 circulation and its clinical impact.

\section{Methods}

French enterovirus surveillance network

EV surveillance in France involves 34 virology/microbiology laboratories in university and general hospitals, including the two EV National Reference Laboratories (NRLs) (based in Lyon and Clermont-Ferrand). Each laboratory reports monthly on a specific website (http:// cnr.chu-clermontferrand.fr/CNR) the number and type of samples analysed for $\mathrm{EV}$, the relevant clinical data and EV serotype (when available). Throughout the year, EV-positive samples including mainly cerebrospinal fluid (CSF) specimens are genotyped in nine laboratories of the EV surveillance network (including the two NRLs) [18]. On 9 October 2014, the French EV surveillance laboratories were contacted by the Lyon NRL to take part in a national EV-D68 surveillance study. Participation in the French EV-D68 project was 
Distribution of human rhinovirus/enterovirus-and enterovirus D68-positive samples per week, France, July-December 2014 ( $n=6,229$ respiratory samples)

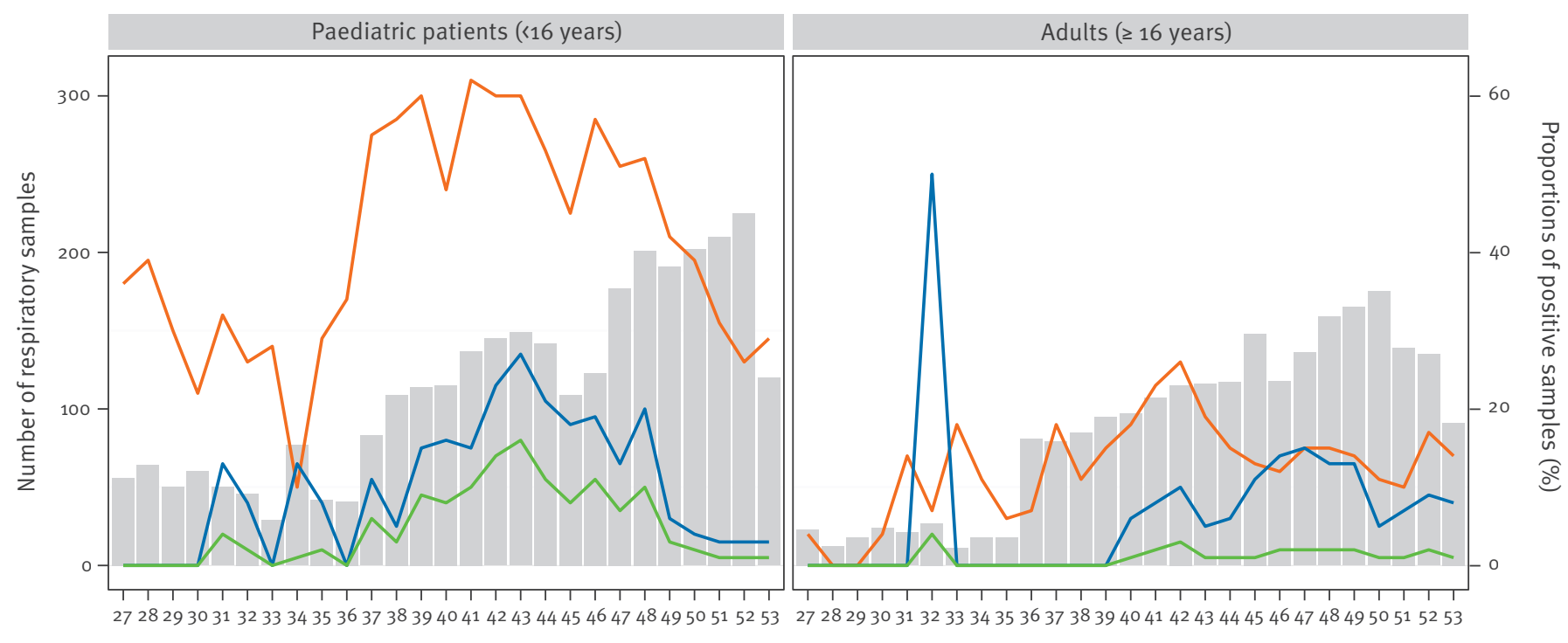

EV: enterovirus; HRV/EV: human rhinovirus/enterovirus.

Orange line: proportion of HRV/EV-positive samples among respiratory samples; green line: proportion of EV-D68-positive samples among respiratory samples; blue line: proportion of EV-D68 among HRV/EV-positive samples; grey histogram: number of respiratory samples tested.

voluntary. Some of the virological data (available as of 1 December, 2014) were also included in a Europeanwide EV-D68 surveillance study [20].

\section{Screening of respiratory samples for enterovirus D68}

Each participating laboratory was requested to test all the respiratory tract specimens collected from 1 July to 31 December 2014 from children ( $\$ 16$ years of age) and adults ( $\geq 16$ years of age) admitted to or visiting the emergency unit of hospitals or university hospitals. Respiratory tract samples were systematically tested for HRV/EV by the RT-PCR assays routinely used at each participating laboratory. EV or HRV/EV-positive samples were thereafter tested for EV-D68 either by a specific EV-D68 real-time RT-PCR assay [17] or by sequencing of the partial viral protein (VP) $4-V P 2$ sequences [21]. The sensitivity of the HRV/EV and the EV-D68 assays was initially evaluated in each laboratory with a titrated aliquot of the Fermon strain provided by the Lyon NRL. Detection of HRV/EV and EV-D68 in samples was performed either in the participating laboratories, or at the NRLs. Besides HRV/EV screening, all other viral and bacteriological tests were performed according to the physicians' requests.

\section{Molecular typing of enterovirus D68-positive} samples and phylogenetic analyses

Complete $\mathrm{VP}_{1}$ sequences of EV-D68 strains were amplified using EV-D68-specific in-house primers and sequenced using the Sanger method. When a complete $\mathrm{VP}_{1}$ sequence could not be obtained, a partial
$V P_{1}$ or $V P_{4}-\mathrm{VP}_{2}$ sequence was determined [21-23]. All the sequences were generated by the EV NRLs and deposited into the GenBank database under accession numbers KP196362-78, KP307989-92, KP40646796, KT220441-6, KT220448-505, LN681318-38, and LN874222-53.

A nucleotide (nt) alignment (340 nt, $\mathrm{n}=391$ ) including all the EV-D68 VP1 sequences available from GenBank (as of 4 June, 2015) and those determined in this study was compiled. Redundant sequences (sharing $100 \%$ nt homology) were discarded. Phylogenetic relationships between sequences were inferred using a Bayesian method implemented in the Bayesian Evolutionary Analysis Sampling Trees (BEAST) package (v1.7) (http://beast.bio.ed.ac.uk) [24]. The uncorrelated lognormal molecular clock was employed with a flexible Bayesian skyline plot coalescent prior (15 piece-wise constant groups) and the generalised time reversible (GTR) model of nt substitution. The Markov chains Monte Carlo (MCMC) were run for 200 million generations, with subsampling every 10,000 iterations. Maximum Clade Credibility trees were calculated with the TreeAnnotator programme (v1.5.4). Topological support was assessed by estimating the values of the posterior probability (pp) density of each node.

\section{Patients and clinical characteristics}

For each EV-D68-infected patient, a review of the medical chart was carried out retrospectively to document the following data: age and sex; symptoms including fever $\left(\geq 38.5^{\circ} \mathrm{C}\right)$, cough, rhinitis, pharyngitis, bronchitis 


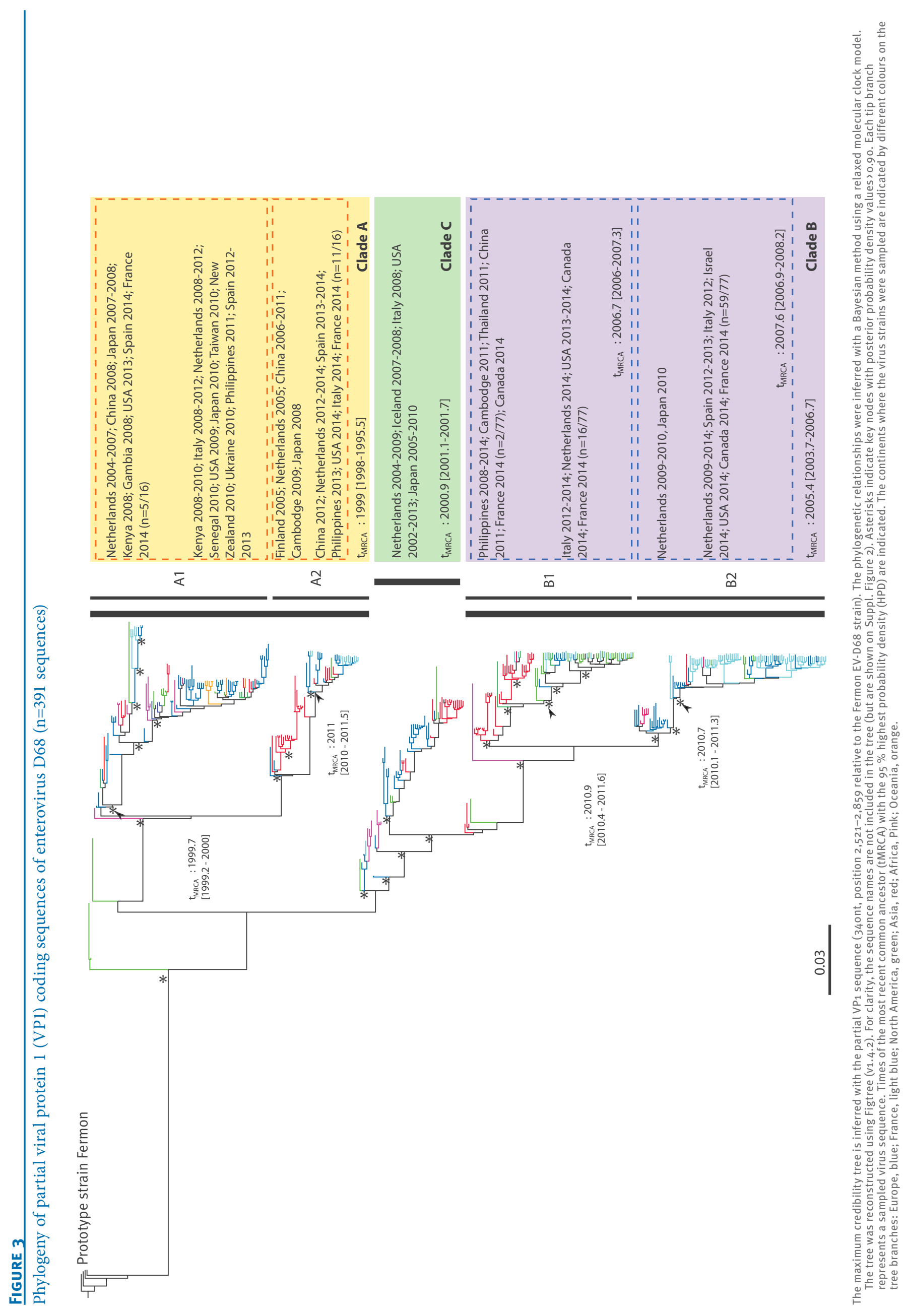


or bronchiolitis, acute respiratory distress, pneumonia, meningitis, polyradiculoneuritis; severity criteria $[25,26]$ at admission such as need for intensive care and/or need for oxygen; length of hospitalisation including in intensive care unit (ICU); final diagnosis; presence or absence of underlying asthma or wheezing, prematurity, atopy, and chronic respiratory disease. Informed consent was not required for this surveillance study. A standardised Excel sheet including all the items was specifically designed for the present study and completed by each participating laboratory. The Lyon NRL compiled and analysed all the anonymised data.

\section{Statistical analysis}

Categorical variables with two or more than two levels (e.g. main diagnosis) were analysed using Fisher's exact test and G-test, respectively. The association between explanatory variables and severity was analysed using univariate logistic regression. Continuous variables (e.g. hospitalisation duration) were treated as binary variables and classified according to their median value. Statistical analysis was conducted using R software.

\section{Results}

\section{Detection and distribution of enterovirus D68 cases}

Eleven laboratories of the French EV network (including the Lyon and Clermont-Ferrand NRLs) participated in the EV-D68 enhanced surveillance. These laboratories were located in eight administrative regions (Table 1). Two of the laboratories analysed only specimens collected from patients under 16 years of age. Performances of the HRV/EV assays and the EV-D68 real-time RT-PCR were comparable among the participating laboratories, as tested on dilutions of a titrated EV-D68 Fermon strain (data not shown).

A total of 6,229 respiratory samples were systematically screened, including 3,645 from children and 2,584 from adults (Table 1). Among the respiratory samples collected from children, 1,501 (41.2\%) were HRV/EV positive, of which 184 (12.3\%) were positive for EV-D68. Among the respiratory samples collected from adults, 368 (14.2\%) were HRV/EV positive, of which 28 (7.6\%) were positive for EV-D68. The overall EV-D68 positivity rates among the respiratory samples tested were of $5.0 \%$ and of $1.1 \%$ in children and adults, respectively (Table 1). Overall the EV-D68-positive respiratory samples $(n=212)$ corresponded to 200 EV-D68 cases including 178 children and 22 adults (Table 1 ).

While routinely genotyping EV-positive clinical samples that had been detected in laboratories not involved in the EV-D68 study, the NRLs identified nine additional cases ( 5 children and 4 adults) during the study period. Seven of these were hospitalised patients and two lived in an elderly nursing home. The nine cases were considered in the overall epidemiological analysis, which therefore comprised a total of 209 cases.

Overall, the first EV-D68 case was detected on 11 July 2014 (Figure 1; week 28). The majority (179/209; 85.6\%) of the EV-D68 cases were detected from weeks 39 to 49 and two peaks could be observed, one in October (week 43) and one in November (week 48).

The samples of the nine cases, which were detected through routine analysis, were not taken into account to calculate positivity rates, which were based on the total of 212 systematically screened respiratory samples. At week 43, in children, the EV-D68-positive samples represented up to $16.1 \%(n=24 / 149)$ of the respiratory samples tested in that week and $26.7 \%(n=24 / 90)$ of the HRV/EV-positive-samples (Figure 2). At week 42, in adults, the EV-D68-positive samples represented up to $2.6 \%(n=3 / 115)$ of the respiratory samples tested and $10 \%(n=3 / 30)$ of the HRV/EV-positive samples (Figure 2). Circulation of the virus persisted until at least the end of December 2014.

EV-D68 infections were detected in all the regions covered by the participating laboratories, i.e. eight of the 22 French administrative regions (Suppl. Figure 1, available from: http://cnr-chu-clermontferrand.fr/CNR/ Pages/Accueil/Publis.aspx).

\section{Clinical characteristics of patients infected by enterovirus D68}

EV-D68 infections were detected in both children and adults (Figure 1). Based on medical chart review and final diagnosis, a bacterium or a parasite was likely to be responsible for the symptoms of six children and five adults. The six paediatric patients presented with arthritis due to Kingella kingae (1 case); pyelonephritis due to Escherichia coli (1 case); gastroenteritis due to norovirus and conjunctivitis due to Haemophilus influenzae (1 case); sepsis due to Streptococcus parasanguis (1 case); febrile syndrome due to Plasmodium falciparum (1 case); meningitis-like syndrome due to Haemophilus influenzae (1 case). The five adult patients had either severe sepsis and acute respiratory distress syndrome (ARDS) due to Pneumocystis carinii or pneumopathy due to Pneumocystis jirovecii (2 cases), Streptocococcus pneumoniae (1 case) or Escherichia coli (1 case). Detailed clinical characteristics of the 11 patients are available upon request. These patients were excluded from the 209 previously described patients, when considering the overall description of clinical characteristics, which thus comprised 198 patients, including 177 children and 21 adults (Table 2). The 11 EV-D68 co-infected patients were also not considered in the univariate analyses that were performed to determine if certain characteristics were associated with disease severity.

Paediatric patients

In the 177 children taken into account to investigate the clinical characteristics, EV-D68 was detected in all age 
TABLE 1

Detection of human rhinovirus/enterovirus and enterovirus D68 through systematic screening of respiratory samples,

France, July-December 2014 ( $\mathrm{n}=6,229$ respiratory samples)

\begin{tabular}{|c|c|c|c|c|c|c|c|}
\hline $\begin{array}{l}\text { Town of the laboratory, } \\
\text { administrative region }\end{array}$ & $\begin{array}{l}\text { Screening } \\
\text { period }\end{array}$ & $\begin{array}{c}\text { RT-PCR assay } \\
\text { used for HRV/EV } \\
\text { detection }\end{array}$ & $\begin{array}{c}\text { Samples } \\
\text { tested for } \\
\text { HRV/EV } \\
n\end{array}$ & $\begin{array}{c}\text { HRV/ } \\
\text { EV-positive } \\
\text { samples } \\
\text { n (\%) }\end{array}$ & $\begin{array}{c}\text { EV-D68- } \\
\text { positive } \\
\text { samples } \\
\text { among HRV/ } \\
\text { EV positive } \\
\text { samples } \\
\text { n (\%) }\end{array}$ & $\begin{array}{c}\text { EV-D68- } \\
\text { positive } \\
\text { samples } \\
\text { among } \\
\text { samples tested } \\
\text { for HRV/EV } \\
\mathrm{n}(\%)\end{array}$ & $\begin{array}{c}\text { EV-D68- } \\
\text { positive } \\
\text { patients } \\
n\end{array}$ \\
\hline \multicolumn{8}{|l|}{ Paediatric patients ( $\$ 16$ years) } \\
\hline Amiens, Picardie & $1 \mathrm{Jul}-31 \mathrm{Dec}$ & $\begin{array}{c}\text { Luminex xTAG RVP } \\
\text { FAST } \\
\end{array}$ & 397 & $125(31.5)$ & $18(14.4)$ & $18(4 \cdot 5)$ & 18 \\
\hline Brest, Bretagne & $1 \mathrm{Jul}-14 \mathrm{Dec}$ & $\begin{array}{l}\text { RespiFinder SMART } \\
22 \text { FAST V2 } \\
\end{array}$ & 142 & $75(52.8)$ & $7(9.3)$ & $7(4.9)$ & 7 \\
\hline Caen, Normandie & $\begin{array}{c}1 \mathrm{Sep}-31 \\
\mathrm{Dec}\end{array}$ & $\begin{array}{l}\text { RespiFinder SMART } \\
22 \text { FAST V2 } \\
\end{array}$ & 614 & $353(57.5)$ & $50(14.2)$ & $50(8.1)$ & 48 \\
\hline Clermont-Ferrand, Auvergne & $1 \mathrm{Jul}-31 \mathrm{Dec}$ & $\begin{array}{c}\text { Rhino and } \mathrm{EV} / \mathrm{Cc} \\
\mathrm{r} \text {-gene }\end{array}$ & 289 & $121(41.9)$ & $24(19.8)$ & $24(8.3)$ & 23 \\
\hline Dijon, Bourgogne & $1 \mathrm{Jul}-31 \mathrm{Dec}$ & $\begin{array}{l}\text { Rhino and } \mathrm{EV} / \mathrm{Cc} \\
\text { r-gene }\end{array}$ & 115 & $36(31.3)$ & $6(16.7)$ & $6(5.2)$ & 5 \\
\hline Lyon, Rhône-Alpes & $1 \mathrm{Jul}-31 \mathrm{Dec}$ & $\begin{array}{l}\text { Rhino and } \mathrm{EV} / \mathrm{Cc} \\
\text { r-gene }\end{array}$ & 1,060 & $349(32.9)$ & $35(10.0)$ & $35(3.3)$ & 33 \\
\hline Paris, Ile de France (Saint Louis) & 1 Jul-7 Dec & $\begin{array}{c}\text { RespiFinder SMART } \\
22 \text { FAST v2 }\end{array}$ & 77 & $35(45 \cdot 5)$ & $0(0.0)$ & $0(0.0)$ & 0 \\
\hline Paris, Ile de France (Paul Brousse) & $1 \mathrm{Jul}-31 \mathrm{Dec}$ & $\begin{array}{c}\text { Rhino and EV/Cc } \\
\text { r-gene }\end{array}$ & 321 & $122(38.0)$ & $6(4.9)$ & $6(1.9)$ & 6 \\
\hline Saint-Etienne, Rhône-Alpes & $\begin{array}{l}10 \text { Oct-31 } \\
\text { Dec }\end{array}$ & $\begin{array}{c}\text { Rhino and } E V / C c \\
r \text {-gene }\end{array}$ & 204 & $80(39.2)$ & $14(17.5)$ & $14(6.9)$ & 14 \\
\hline Strasbourg, Alsace & $\begin{array}{c}19 \text { Sep-31 } \\
\text { Dec }\end{array}$ & $\begin{array}{c}\text { Luminex xTAG RVP } \\
\text { FAST }\end{array}$ & 304 & $147(48.4)$ & $11(7.5)$ & $11(3.6)$ & 11 \\
\hline Versailles, Ile de France & $1 \mathrm{Jul}-31 \mathrm{Dec}$ & $\begin{array}{c}\text { Rhino and EV/Cc } \\
\text { r-gene }\end{array}$ & 122 & $58(47.5)$ & $13(22.4)$ & $13(10.7)$ & 13 \\
\hline Total & - & - & 3,645 & $1,501(41.2)$ & $184(12.3)$ & $184(5.0)$ & 178 \\
\hline \multicolumn{8}{|l|}{ Adult patients ( $\geq 16$ years) } \\
\hline Amiens, Picardie & $1 \mathrm{Jul}-31 \mathrm{Dec}$ & $\begin{array}{c}\text { Luminex xTAG RVP } \\
\text { FAST } \\
\end{array}$ & 216 & $36(16.7)$ & $7(19.4)$ & $7(3.2)$ & 4 \\
\hline Brest, Bretagne & $1 \mathrm{Jul}-14 \mathrm{Dec}$ & $\begin{array}{c}\text { RespiFinder SMART } \\
22 \text { FAST v2 }\end{array}$ & 130 & $29(22.3)$ & $4(13.8)$ & $4(3.1)$ & 4 \\
\hline Caen, Normandie & $\begin{array}{l}1 \text { Sep-31 } \\
\text { Dec }\end{array}$ & $\begin{array}{l}\text { RespiFinder SMART } \\
22 \text { FAST V2 } \\
\end{array}$ & 416 & $78(18.8)$ & $1(1.3)$ & $1(0.2)$ & 1 \\
\hline Clermont-Ferrand, Auvergne & $1 \mathrm{Jul}-31 \mathrm{Dec}$ & $\begin{array}{l}\text { Rhino and } E V / C c \\
\text { r-gene }\end{array}$ & 367 & $54(14.7)$ & $4(7.4)$ & $4(1.1)$ & 3 \\
\hline Dijon, Bourgogne & $1 \mathrm{Jul}-31 \mathrm{Dec}$ & $\begin{array}{l}\text { Rhino and } E V / C c \\
\text { r-gene }\end{array}$ & 214 & $25(11.7)$ & $1(4.0)$ & $1(0.5)$ & 1 \\
\hline Lyon, Rhône-Alpes & $\begin{array}{c}1 \text { Sep-31 } \\
\text { Dec }\end{array}$ & $\begin{array}{l}\text { Rhino and } \mathrm{EV} / \mathrm{CC} \\
\text { r-gene }\end{array}$ & 1,036 & $123(11.9)$ & $11(8.9)$ & $11(1.1)$ & 9 \\
\hline Paris, Ile de France (Paul Brousse) & $1 \mathrm{Jul}-31 \mathrm{Dec}$ & $\begin{array}{l}\text { Rhino and } \mathrm{EV} / \mathrm{CC} \\
\text { r-gene }\end{array}$ & 40 & $7(17.5)$ & $0(0.0)$ & $0(0.0)$ & 0 \\
\hline Saint-Etienne, Rhône Alpes & $\begin{array}{l}10 \text { Oct-31 } \\
\text { Dec }\end{array}$ & $\begin{array}{l}\text { Rhino and } \mathrm{EV} / \mathrm{Cc} \\
\text { r-gene }\end{array}$ & 41 & $1(2.4)$ & $0(0.0)$ & $0(0.0)$ & 0 \\
\hline Versailles, Ile de France & $1 \mathrm{Jul}-31 \mathrm{Dec}$ & $\begin{array}{l}\text { Rhino and } \mathrm{EV} / \mathrm{Cc} \\
\text { r-gene }\end{array}$ & 124 & $15(12.1)$ & $0(0.0)$ & $0(0.0)$ & 0 \\
\hline Total & - & - & 2,584 & $368(14.2)$ & $28(7.6)$ & $28(1.1)$ & 22 \\
\hline
\end{tabular}

EV: enterovirus; HRV/EV: human rhinovirus/enterovirus; RT-PCR: reverse-transcription polymerase chain reaction.

The study involved 11 voluntary laboratories of the 34 in the EV surveillance network (including two different virology laboratories from the Paris area). A total of 212 EV-D68-positive samples corresponding to 200 EV-D68 cases were detected by the systematic screening of respiratory tract samples collected from children ( 16 years-old) and adults ( $\geq 16$ years-old) admitted to or visiting emergency units of hospitals or university hospitals. 
groups and the most affected age group was $<2$ years ( 2 years: 76 patients, including $\leq 28$ days: 6 patients; 2-5 years: 73 patients; $6-15$ years: 28 patients). The median age of the patients was 2.33 years (range: 3 days -13.5 years). Information on hospitalisation was available for 174 patients. A total of 160/174 (92.0\%) patients were hospitalised and $14 / 174$ (8.0\%) were outpatients (short stay at the emergency unit but no overnight hospitalisation). A final diagnosis was available for $173(97.7 \%)$ patients and a total of $166 / 173$ (96.0\%) presented with acute respiratory infections. The main diagnoses were asthma $(n=83 ; 48.0 \%)$ and bronchiolitis ( $n=37 ; 21.4 \%)$. Other diagnoses are summarised in Table 2. Among the children hospitalised for asthma (82/83; Table 2), 64 (78.0\%) had a previous history of asthma or wheezing. In univariate analysis however, the history of asthma or wheezing as a determinant of severity or hospitalisation in ICU was not statistically significant (Table 3).

Four patients (2.3\%) presented with neurological signs (Table 2). One four-year-old patient developed AFP following EV-D68 associated pneumonia; CSF showed pleocytosis with normal protein and glucose levels and spinal magnetic resonance imagery showed gadolinium enhancement of the ventral nerve roots of the cauda equine [19]. One patient aged 20 months developed meningitis-like symptoms. Two infants with underlying epilepsy developed severe seizures in a context of bronchiolitis or pneumonia. Three children presented with isolated neonatal fever, one with a severe sepsis syndrome and one with hypotonia. One EV-D68 infection was diagnosed in the context of a sudden infant death syndrome (SIDS) in a two-month-old girl; detection of EV-D68 in blood was negative and no other pathogen was detected.

Nineteen children (10.7\%) were hospitalised in ICUs (median duration: 3 days; range: 1-137 days) (Table 2). Of these, two ex-premature babies with bronchopulmonary dysplasia were infected by EV-D68 while already in neonatal ICU and developed severe respiratory decompensation. Among the 17 remaining patients (see clinical presentation in Table 2), 15 had pre-existing chronic conditions (prematurity: 4; asthma/wheezing: 9; pulmonary vein atresia: 1, ventricular septal defect: 1, drepanocytosis: 1; epilepsy: 2) and two patients, who presented with pneumothorax (without asthma) or AFP, had no underlying disease. All but one patient hospitalised in ICU had favourable outcomes. The patient who developed AFP was extubated after 4.5 months in ICU, but still showed severe sequelae of right upper limb after 12 months. No death could be directly imputed to EV-D68.

\section{Adult patients}

The median age of the 21 adult patients was 36.7 years (range: 17.2-98.9 years). Fourteen were hospitalised and five were outpatients ( 2 patients not documented) (Table 2). A diagnosis and clinical signs were available for 17 patients. The diagnoses were as follows: asthma ( $\mathrm{n}=4$; all with underlying history of asthma); pneumonia $(n=4)$, chronic obstructive pulmonary disease (COPD) exacerbation $(n=3$; all with stage III COPD), upper respiratory tract infection $(n=2)$, bronchitis $(n=1)$, influenza-like illness $(n=1)$ and pneumothorax $(n=1)$. One patient was asymptomatic (allograft follow-up).

Three patients were hospitalised in ICU for two, three and six days, respectively; two of them presented with pneumonia: a 25 year-old patient who developed a severe respiratory distress without underlying risk factors during the week 29 of gestation and a 23 year-old patient with underlying Duchenne muscular dystrophy; the third patient presented with exacerbation of COPD. All the adult cases had favourable outcomes.

\section{Enterovirus D68 sequencing and phylogenetic analysis}

EV-D68 was tentatively sequenced in 207 of 209 patients. Among these 207, EV-D68 infection was confirmed in 201 patients either by VP1 sequencing $(n=179)$ or by $V_{4}-V P_{2}$ sequencing $(n=22)$. In six patients, the virus could not be sequenced, probably because of the low viral load (cycle thresholds of EV-D68 real-time RT-PCRs were between 39.3 and 40.7). A total of $178 / 201$ (88.6\%) EV-D68 viruses belonged to clade B and 23/201 (11.4\%) belonged to clade A [27]. Of the 159 clade $B$ viruses for which the VP1 sequence was obtained, 42 (26.4\%) and 117 (73.6\%) were assigned to the sublineage $B_{1}$ and $B 2$, respectively (data not shown). Clade $A$ and $B$ viruses were identified throughout the screening period and the proportion of $A$ and $B$ viruses per week did not vary significantly (data not shown). Clade A viruses were detected more frequently in adults $(10 / 23,43.5 \%)$ than in children (13/178, 7.3\%) ( $p<0.001$ ). Proportions of $A$ and $B$ viruses did not differ significantly between patients hospitalised in ICU and patients not hospitalised in ICU.

To investigate a large sample drawn from different geographical origins, a Bayesian analysis was performed on partial VP1 sequences, including those of 93 viruses from France and 298 viruses from other geographical regions (Figure 3 and Suppl. Figure 2, available from: http://cnr-chu-clermontferrand.fr/CNR/Pages/Accueil/ Publis.aspx). The results suggested that all the recent EV-D68 strains formed one genogroup which could be further divided in two major lineages: the first corresponded to clade $A$ lineage while the second included clades B and C [27]. This phylogenetic topology was confirmed by a Bayesian analysis on complete VP1 sequences (data not shown) and was concordant with the topology described by Lauinger et al. [11]. Sixteen French strains fell within the clade $A$ and clustered in two highly supported lineages (posterior probability, $p p>0.97$ ) designated $A_{1}\left(n=5\right.$ strains) and $A_{2}$ $\left(n=11\right.$ strains). The French $A_{1}$ viruses clustered with strains collected in 2013-2014 in the US, Spain and the Netherlands. The French $A_{2}$ viruses clustered with viruses recovered between 2012 and 2014 from three 
TABLE 2

Clinical characteristics of enterovirus D68 cases, France, July-December $2014\left(\mathrm{n}=198\right.$ patients) ${ }^{\mathrm{a}}$

\begin{tabular}{|c|c|c|c|c|c|c|}
\hline \multirow[b]{2}{*}{ Characteristic } & \multicolumn{3}{|c|}{ Paediatric patients ( 16 years) } & \multicolumn{3}{|c|}{ Adult patients ( $\geq 16$ years) } \\
\hline & $\begin{array}{l}\text { Patients } \\
\mathrm{N}\end{array}$ & $\begin{array}{l}\text { Hospitalised } \\
\text { patients } \\
\text { N }\end{array}$ & $\begin{array}{c}\text { Patients in ICU } \\
N\end{array}$ & $\begin{array}{l}\text { Patients } \\
\mathrm{N}\end{array}$ & $\begin{array}{l}\text { Hospitalised } \\
\text { patients } \\
\mathrm{N}\end{array}$ & $\begin{array}{l}\text { Patients in } \\
\text { ICU } \\
\text { N }\end{array}$ \\
\hline Sex-ratio (M/F) & \multicolumn{3}{|c|}{$1.39(103 / 74)$} & \multicolumn{3}{|c|}{$0.62(8 / 13)$} \\
\hline Median hospitalisation duration & \multicolumn{3}{|c|}{4 days (range: $1-172$ days) $(n=147)^{b}$} & \multicolumn{3}{|c|}{3 days $(2-18)(n=12)^{b}$} \\
\hline $\begin{array}{l}\text { Median hospitalisation duration in } \\
\text { ICU }\end{array}$ & \multicolumn{3}{|c|}{3 days (range: $1-132$ days) $(n=17)^{b}$} & \multicolumn{3}{|c|}{3 days $(2-6)(n=3)$} \\
\hline $\begin{array}{l}\text { Number of patients with oxygen } \\
\text { therapy }\end{array}$ & \multicolumn{3}{|c|}{$78(\mathrm{n}=171)^{\mathrm{b}, \mathrm{c}}$} & \multicolumn{3}{|c|}{$6(n=17)^{b, d}$} \\
\hline $\begin{array}{l}\text { Number of patients with history of } \\
\text { asthma/wheezing }\end{array}$ & \multicolumn{3}{|c|}{$85(n=168)^{b}$} & \multicolumn{3}{|c|}{$4(n=10)^{b}$} \\
\hline \multicolumn{7}{|l|}{ Respiratory presentation } \\
\hline Asthma & $83^{\mathrm{e}}$ & $82^{\mathrm{e}}$ & 8 & 4 & 4 & 0 \\
\hline Severe asthma & $24^{e}$ & $24^{e}$ & 8 & 1 & 1 & 0 \\
\hline Bronchiolitis & $37^{\mathrm{e}}$ & $34^{\mathrm{e}}$ & $4^{f}$ & 0 & 0 & 0 \\
\hline Severe bronchiolitis & $4^{e}$ & $4^{e}$ & $4^{f}$ & $o$ & 0 & 0 \\
\hline COPD exacerbation & 0 & 0 & o & 3 & 3 & 1 \\
\hline Respiratory distress only & 4 & 4 & 3 & o & o & 0 \\
\hline Pneumonia & $11^{\mathrm{e}}$ & $11^{\mathrm{e}}$ & $1^{f}$ & 4 & 4 & 2 \\
\hline Upper respiratory tract infection & 26 & 18 & 0 & 2 & 0 & 0 \\
\hline Other & $7^{\mathrm{g}}$ & 7 & 2 & $3^{\mathrm{h}}$ & 2 & 0 \\
\hline \multicolumn{7}{|l|}{ Neurological presentation } \\
\hline Acute flaccid paralysis & 1 & 1 & 1 & 0 & 0 & 0 \\
\hline Seizures & $2^{\mathrm{e}}$ & $2^{\mathrm{e}}$ & $2^{f}$ & o & 0 & o \\
\hline Other & $\begin{array}{c}1 \\
\text { (meningitis-like) } \\
\end{array}$ & 1 & 0 & o & 0 & 0 \\
\hline \multicolumn{7}{|l|}{ Other presentation } \\
\hline Hypotonia & 1 & 1 & 0 & 0 & 0 & 0 \\
\hline Neonate fever $\left(\geq 38.5^{\circ} \mathrm{C}\right)$ & 3 & 2 & 0 & o & 0 & 0 \\
\hline Other & $2^{i}$ & 1 & o & o & 0 & o \\
\hline Asymptomatic & 0 & 0 & 0 & $1^{j}$ & 0 & 0 \\
\hline Not documented & 4 & 1 & 0 & 4 & 1 & 0 \\
\hline Total & 177 & 160 & 19 & 21 & 14 & 3 \\
\hline
\end{tabular}

COPD: chronic obstructive pulmonary disease; EV: enterovirus; F: female; ICU: intensive care unit; M: male.

A given patient could have more than one clinical characteristic.

${ }^{a}$ We excluded six paediatric and five adult patients for whom the clinical signs were likely to be due to a bacterium or a parasite, from the total of 209 cases.

${ }^{b}$ The number of patients for whom the information was available is indicated in parentheses.

c Two ex-premature babies with bronchodysplasia were already under continuous oxygen therapy.

${ }^{d}$ Four patients with underlying COPD $(n=3)$ or Duchenne muscular dystrophy $(n=1)$ were already under continuous oxygen therapy.

e Three patients presented with asthma and pneumonia; one patient with bronchiolitis and seizures; one with pneumonia and seizures.

${ }^{f}$ One patient presented with bronchiolitis and seizures; one with pneumonia and seizures.

${ }^{g}$ Pneumothorax $(n=1)$; acute thoracic syndrome $(n=1)$; bronchitis $(n=5)$.

h Influenza-like illness $(n=1)$; pneumothorax $(n=1)$; bronchitis $(n=1)$.

' Infant sepsis $(\mathrm{n}=1)$; sudden infant death syndrome $(\mathrm{n}=1)$.

i Allograft follow-up.

different continents. The remaining 77 French strains belonged to two lineages designated B1 ( $p p=0.94$; $\mathrm{n}=18$ strains) and $\mathrm{B} 2(\mathrm{pp}=1 ; \mathrm{n}=59)$ within the clade $\mathrm{B}$. The $\mathrm{B}_{1}$ lineage included most of the strains sampled in 2014 in the US and 18 French strains, while the B2 lineage was almost exclusively composed of strains recovered in Europe and comprised the majority of strains detected in France in 2014 (59/93, 63.4\%). The AFP case was associated with a B2 strain [19]. The EV-D68 sequences detected in Europe between 2012 and 2014 were closely related to those from viruses detected in 2014 in Israel $(n=2)$, US $(n=4)$ and Canada $(n=1)$.

\section{Discussion}

From mid-August 2014 until the end of December, EV-D68 caused a geographically widespread outbreak of respiratory disease of unprecedented magnitude in the US, leading to substantial hospitalisation for 
Univariate analysis of potential factors for severe disease in children infected with enterovirus D68, France, July-December $2014(\mathrm{n}=177)$

\begin{tabular}{|c|c|c|c|c|c|c|c|c|c|c|c|c|c|c|c|c|}
\hline \multirow[b]{2}{*}{ Characteristic } & \multicolumn{4}{|c|}{ Severity ${ }^{\mathrm{a}}$} & \multicolumn{4}{|c|}{ ICU admission } & \multicolumn{4}{|c|}{ Oxygen therapy } & \multicolumn{4}{|c|}{ Hospitalisation duration ${ }^{b}$} \\
\hline & No & Yes & OR $(95 \% \mathrm{Cl})$ & $P$ & No & Yes & $\begin{array}{c}\text { OR } \\
(95 \% \\
\text { Cl) }\end{array}$ & $\mathrm{P}$ & No & Yes & $\begin{array}{c}\text { OR } \\
(95 \% \\
\text { CI) }\end{array}$ & $\mathrm{p}$ & $\begin{array}{l}\leq 4 \\
\text { days }\end{array}$ & $\begin{array}{c}>4 \\
\text { days }\end{array}$ & $\begin{array}{c}\text { OR }(95 \% \\
\text { Cl) }\end{array}$ & $\mathrm{P}$ \\
\hline
\end{tabular}

Sex

\begin{tabular}{|c|c|c|c|c|c|c|c|c|c|c|c|c|c|c|c|c|}
\hline Male & $75^{\mathrm{a}}$ & $23^{a}$ & \multirow{2}{*}{$\begin{array}{l}0.90 \\
(0.44-1.85)\end{array}$} & \multirow{2}{*}{0.7781} & 90 & 12 & \multirow{2}{*}{\begin{tabular}{|l|}
1.22 \\
$(0.46-$ \\
$3.43)$ \\
\end{tabular}} & \multirow{2}{*}{0.6937} & 54 & 45 & \multirow{2}{*}{$\begin{array}{l}0.98 \\
(0.54- \\
1.82) \\
\end{array}$} & \multirow{2}{*}{0.9608} & 55 & 30 & \multirow{2}{*}{$\begin{array}{l}1.06 \\
(0.54-2.14)\end{array}$} & \multirow[b]{2}{*}{0.8579} \\
\hline Female & $53^{\mathrm{a}}$ & $18^{\mathrm{a}}$ & & & 64 & 7 & & & 39 & 33 & & & 41 & 21 & & \\
\hline \multicolumn{17}{|c|}{ Prematurity } \\
\hline Yes & 18 & 6 & \multirow{2}{*}{$\begin{array}{l}0.99 \\
(0.34-2.57)\end{array}$} & \multirow[b]{2}{*}{0.9850} & 20 & 4 & \multirow{2}{*}{\begin{tabular}{|l}
1.72 \\
$(0.46-$ \\
$5.32)$
\end{tabular}} & \multirow[b]{2}{*}{0.3755} & 15 & 9 & \multirow{2}{*}{$\begin{array}{l}0.65 \\
(0.26- \\
1.57)\end{array}$} & \multirow[b]{2}{*}{0.3476} & 8 & 8 & \multirow{2}{*}{$\begin{array}{l}2.07 \\
(0.72-6.02)\end{array}$} & \multirow[b]{2}{*}{0.1729} \\
\hline No & 104 & 35 & & & 129 & 15 & & & 74 & 68 & & & 85 & 41 & & \\
\hline
\end{tabular}

History of asthma or wheezing

\begin{tabular}{|c|c|c|c|c|c|c|c|c|c|c|c|c|c|c|c|c|}
\hline Yes & 59 & 22 & \multirow{2}{*}{$\begin{array}{l}1.30 \\
(0.64-2.65)\end{array}$} & \multirow{2}{*}{0.4733} & 76 & 8 & \multirow{2}{*}{\begin{tabular}{|l|}
0.72 \\
$(0.26-$ \\
$1.87)$ \\
\end{tabular}} & \multirow[b]{2}{*}{0.5005} & 32 & 51 & \multirow{2}{*}{\begin{tabular}{|l|}
3.48 \\
$(1.86-$ \\
$6.65)$
\end{tabular}} & \multirow[b]{2}{*}{0.0001} & 50 & 26 & \multirow{2}{*}{$\begin{array}{l}0.98 \\
(0.49-1.94)\end{array}$} & \multirow[b]{2}{*}{0.9423} \\
\hline No & 66 & 19 & & & 75 & 11 & & & 59 & 27 & & & 45 & 24 & & \\
\hline
\end{tabular}

History of atopy

\begin{tabular}{|c|c|c|c|c|c|c|c|c|c|c|c|c|c|c|c|c|}
\hline Yes & 18 & 8 & \multirow{2}{*}{$\begin{array}{l}1.49 \\
(0.57-3.67)\end{array}$} & \multirow[b]{2}{*}{0.3970} & 27 & 2 & \multirow{2}{*}{\begin{tabular}{|l|}
0.60 \\
$(0.09-$ \\
$2.31)$
\end{tabular}} & \multirow[b]{2}{*}{0.5171} & 13 & 16 & \multirow{2}{*}{$\begin{array}{l}1.59 \\
(0.71- \\
3.6)\end{array}$} & \multirow[b]{2}{*}{0.2630} & 21 & 8 & \multirow{2}{*}{$\begin{array}{l}0.65 \\
(0.25-1.55)\end{array}$} & \multirow[b]{2}{*}{0.3494} \\
\hline No & 104 & 31 & & & 122 & 15 & & & 76 & 59 & & & 70 & 41 & & \\
\hline
\end{tabular}

History of chronic respiratory insufficiency

\begin{tabular}{|c|c|c|c|c|c|c|c|c|c|c|c|c|c|c|c|c|}
\hline Yes & 3 & 4 & \multirow{2}{*}{$\begin{array}{l}4.29 \\
(0.91-22.6)\end{array}$} & \multirow[b]{2}{*}{0.0642} & 5 & 2 & \multirow{2}{*}{$\begin{array}{l}3.39 \\
(0.46- \\
17.12)\end{array}$} & \multirow[b]{2}{*}{0.1632} & 4 & 3 & \multirow{2}{*}{$\begin{array}{l}0.86 \\
(0.17- \\
4.03)\end{array}$} & \multirow[b]{2}{*}{0.8484} & 0 & 3 & \multirow[b]{2}{*}{ NA (NA) } & \multirow[b]{2}{*}{ NA } \\
\hline No & 119 & 37 & & & 144 & 17 & & & 85 & 74 & & & 92 & 47 & & \\
\hline
\end{tabular}

\section{EV-D68 clade}

\begin{tabular}{|c|c|c|c|c|c|c|c|c|c|c|c|c|c|c|c|c|}
\hline A & 9 & 1 & \multirow{2}{*}{$\begin{array}{l}3.03 \\
(0.54-56.72)\end{array}$} & \multirow{2}{*}{0.3009} & 10 & 1 & \multirow{2}{*}{\begin{tabular}{|l}
1.32 \\
$(0.23-$ \\
$25)$
\end{tabular}} & \multirow{2}{*}{0.7949} & 5 & 6 & \multirow{2}{*}{$\begin{array}{l}0.71 \\
(0.2- \\
2.46)\end{array}$} & \multirow{2}{*}{0.5870} & 8 & 1 & \multirow{2}{*}{$\begin{array}{l}4.38(0.77- \\
82.55)\end{array}$} & \multirow{2}{*}{0.1699} \\
\hline B & 113 & 38 & & & 136 & 18 & & & 82 & 70 & & & 84 & 46 & & \\
\hline
\end{tabular}

Age

\begin{tabular}{|l|l|l|l|l|l|l|l|l|l|l|l|l|l|l|l|l|}
\hline$<2$ years & 59 & 15 & Ref & Ref & 64 & 10 & Ref & Ref & 40 & 33 & Ref & Ref & 35 & 28 & Ref & Ref \\
\hline $2-5$ years & 44 & 15 & $\begin{array}{l}1.34 \\
(0.59-3.05)\end{array}$ & 0.4806 & 56 & 5 & $\begin{array}{l}0.57 \\
(0.17- \\
1.71)\end{array}$ & 0.3325 & 30 & 31 & $\begin{array}{l}1.25 \\
(0.63- \\
2.48)\end{array}$ & 0.5173 & 41 & 13 & $\begin{array}{l}0.4 \\
(0.17-0.87)\end{array}$ & $\begin{array}{l}0.0230 \\
\text { >5 years }\end{array}$ \\
\hline 25 & 11 & $\begin{array}{l}1.73 \\
(0.69-4.29)\end{array}$ & 0.2363 & 34 & 4 & $\begin{array}{l}0.75 \\
(0.19- \\
2.44)\end{array}$ & 0.6516 & 23 & 14 & $\begin{array}{l}0.74 \\
(0.32- \\
1.64)\end{array}$ & 0.4611 & 20 & 10 & $\begin{array}{l}0.63 \\
(0.25-1.53)\end{array}$ & 0.3100 \\
\hline
\end{tabular}

CI: confidence interval; EV: enterovirus; ICU: intensive care unit; NA: not applicable because of the small number of reports; OR: odds ratio; P:p-value; Ref: reference.

a Severity criteria were defined as elsewhere $[25,26]$ and included the need for intensive care and need for oxygen. Severity criteria were only known for 169 cases.

${ }^{b}$ Dichotomised according to median value. Median hospitalisation time (for inpatients) was four days.

severe respiratory disease. In the context of the US alert, a systematic screening of EV-D68 was performed by 11 voluntary hospital laboratories of the French EV surveillance network on 6,229 respiratory samples collected between 1 July and 31 December 2014 .

This report concerns the largest number of EV-D68 cases ever documented for France. Due to the implementation of systematic screening of EV-D68, a total of 200 EV-D68 infections were diagnosed and EV-D68 was detected in all the administrative regions from where the participating laboratories were involved (i.e. 8 of the 22 administrative regions), suggesting that EV-D68 might have circulated even more widely throughout the country. Previously, two small clusters of cases had been reported in 2008 (19 cases; Oct-Nov; BasseNormandie region) and 2009 (10 cases; Sep-Nov;
Champagne-Ardennes region), respectively $[8,9]$ and only 66 EV-D68 cases were reported to the National Institute for Public Health between 2006 and 2013. However, during the 2007 to 2013 period, EV-D68 infections were probably underestimated, because HRV/EV screening in ARI was restricted to a limited number of laboratories (particularly before 2010), genotyping of HRV/EV-positive samples was rarely performed and the specific detection of EV-D68 by real-time RT-PCR was unavailable. On the other hand, no EV-D68 case was detected by systematic screening of respiratory samples collected in Lyon from September until December 2013 (data not shown), whereas 42 cases were identified between July and December 2014. This suggests that the circulation level of EV-D68 was higher in 2014 than in 2013, at least in the Lyon area and possibly elsewhere in France. In this respect, surveillance studies in 
the Philippines [28], Italy [10] and the Netherlands [7] showed that EV-D68 may follow a cyclic pattern of circulation with a two-year interval.

The overall EV-D68 detection rate that we observed in a hospital-based setting between July and December 2014 in France (3.4\%; maximum 8.4\% on week 43) was similar to that observed in a European-wide survey (2.1\% [20]) conducted on 17,384 respiratory samples from 17 countries collected mainly from hospitalised patients between July and November 2014 - and in which the virological results for 117 French patients, available as of 1 December, 2014, were included. It was much lower than that reported by the $C D C$ during the August to December period (36\% of 2,600 respiratory samples) (http://www.cdc.gov/non-polio-enterovirus/ about/EV-D68.html). However, the proportion reported by the CDC was calculated mainly from severe cases, which may hamper comparisons. Comparison between findings in France and the US may also be hampered by increased public/physician awareness and more active case finding in the US.

At the time of the US alert, and despite existing surveillance systems for respiratory tract illness (RTI) or influenza-like illness $[29,30]$, no upsurge of the number of hospitalisations for RTI, or of the number of HRV/EV positive respiratory samples, was reported in France. This suggests that the impact of the circulation of EV-D68 on public health was more limited in France and Europe than in the US and may explain why only rare alerts were reported in Europe [15-17].

Our longitudinal study provided a comprehensive description of the epidemiological and clinical characteristics of EV-D68 infections in hospitalised patients during the entire study period. Most cases (87.5\%) were detected in children, as observed in the US [14]. The EV-68 detection rate in respiratory samples from children was of $9.7 \%(n=100 / 1,035)$ in the September to October period and was similar to that observed at the same period in hospitalised children from the Oslo area [16]. Most children (93\%) with an EV-D68 infection presented with respiratory symptoms, mainly asthma and bronchiolitis, as described in hospitalised patients in the 2014 US outbreak, an outbreak in Canada in the same year, and in previous reports $[6,8,13,14,31]$. EV-D68 could also be associated with respiratory distress without underlying asthma or bronchiolitis, especially in ex-premature babies with bronchopulmonary dysplasia. Among the children who were hospitalised for asthma, $78 \%$ had a history of asthma or wheezing, consistent with US reports. In our study, underlying asthma or wheezing was not identified as a risk factor for developing more severe asthma or being hospitalised in ICU, however statistical power may have been limited by the sample size.

Viral factors may also contribute to the disease. Even though identical VP1 sequences were detected in both mild and severe RTI cases, full length analysis of viral genomes is warranted to determine whether specific mutations in coding or non-coding regions influence severity, as observed for poliovirus or EV-A71 [32,33].

Neurological signs were observed in four patients. Only one AFP case was reported during this survey [19] and no increase in AFP cases was reported to the public health authorities during the EV-D68 circulation period. For the three remaining cases of patients with meningitis-like symptoms or with seizures, although such disease manifestations have not been previously described with EV-D68, they are frequently associated with EV infections particularly in young children. However, we cannot rule out the possibility that other viral or bacterial infection could have contributed to these neurological signs. Of note, in 2014, no EV-D68 was detected in 1,197 CSF specimens genotyped throughout the EV national surveillance. So, apart from the AFP-associated case, the spectrum of illnesses associated with EV-D68 was similar to that of rhinoviruses, as previously reported $[1,3-10,13,14,16,17,19,31]$. Although no significant increase in severe respiratory disease was reported to the French national public health authorities in autumn 2014, the present study showed that EV-D68 did have a clear clinical impact, with $10.7 \%$ of the paediatric cases and $14.3 \%$ of the adult cases being hospitalised in ICUs. Moreover, its implication in nosocomial infections should be considered $[17,34]$. This highlights the need for clinical laboratories to take EV-D68 in account in the differential diagnosis of patients with severe respiratory symptoms, including in adult patients.

EV-D68 infections in France in 2014 were mainly associated with the B2 variant, as in other European countries [20]. However, it was not possible to determine whether the B2 variant was circulating in France before 2014 because the molecular characterisation of $\mathrm{EV} / \mathrm{HRV}$-positive respiratory samples is not routinely performed, as exemplified by our finding of only one French EV-D68 VP1 sequence in GenBank from prior to 2014 (sequence from genogroup $C ;$ 1999). In the Netherlands, virus surveillance between 2004 and 2014 provided evidence of the successive replacement of the major lineage by another lineage in each period of increased virus reporting. While clade $C$ predominated until 2008, an outbreak in 2010 was mainly associated with the circulation of clade A strains [7]. The B2 viruses also circulated in 2010 but to a lesser extent, $[6,7]$ and became predominant in 2014 [17]. This type of circulation pattern - the replacement of an earlier variant during periods of low virus incidence - is reminiscent of that observed for EV-A71 [35,36]. The succession of predominant lineages could be driven by the immunity of the general population. In this respect, Imamura et al. [37] showed that there were antigenic differences between the recent lineages of EV-D68 circulating strains. Finally, the different lineages were present simultaneously over several countries and continents. The close genetic relatedness between EV-D68 strains sampled from distant countries suggests that 
this virus is subject to frequent geographical turnover. Further studies based on larger samples of complete $V P_{1}$ sequences are needed to investigate the dynamics of EV-D68 geographical transportation between countries and over continents.

This study comprised some limitations. The screening was not population-based as it depended on the voluntary participation of only about one-third of EV network laboratories in France. We also lacked historical EV-D68 screening data at a national level for comparison, and the sample size was limited in terms of the statistical power support in univariate analyses. Moreover, we cannot exclude that respiratory samples may have been collected for viral screening more frequently from children than from adults and that EV-D68 positivity rate may have been underestimated in adults. Our data were however likely not biased towards more severe infections as they were based on testing results of respiratory samples collected for routine viral screening of respiratory infections.

The autumn of 2014 was marked by increased EV-D68 detection in many parts of the world [12-17,31], associated, at least in parts of the US and Canada, with a significant upsurge of severe respiratory infections, sometimes followed by neurological signs. A similar outbreak may possibly also occur in Europe in the future, and the results of our study show that in France, a number of EV-D68 infections had a clinical impact. This justifies the need for continuous surveillance of EV-D68 infections in Europe. The surveillance could rely on existing and effective surveillance programmes such as the influenza and influenza-like illness surveillance systems, the EV surveillance networks and the surveillance of AFP cases. The increasing awareness of $\mathrm{HRV} / \mathrm{EV}$ as major respiratory pathogens and the development of commercial molecular assays for these viruses has allowed the implementation of HRV/EV diagnosis in an increasing number of virology laboratories [33,38]. Moreover, virus characterisation should be encouraged, at least in the event of severe respiratory signs.

\section{Acknowledgements}

We would like to thank Delphine Falcon, Katy Pinet, Chantal Gousse for EV-D68 screening and typing. We are grateful to Nathalie Rodde, Gwendoline Jugie, Emilie Leroy for excellent technical assistance in HRV/EV genotyping. We acknowledge Dr Mélanie Ribault, Dr Matthieu Verdan et Pr André Labbé, Dr Jean-Sébastien Casalegno, Dr Christine Raybaud, Dr Claire Gay, Dr Emmanuelle Laurent, Dr Lucie Molet for collecting clinical data for the EV-D68 cases diagnosed through a systematic approach. We acknowledge Pantxica Bellecave, Marianne Coste-Burel, Gisèle Lagathu and Pierrette Dhont for transmitting clinical data for the EV-D68 cases diagnosed through a non-screening strategy. We are grateful to Lynn Richardson for revision of the English.

Conflict of interest
Authors' contributions

IS designed the study and coordinated the laboratory network involved in this study, together with AM. IS, AM, DH, $\mathrm{LP}, \mathrm{JPL}, \mathrm{CM}, \mathrm{JL}, \mathrm{CD}, \mathrm{SP}, \mathrm{QL}, \mathrm{JMM}$ and SMJ provided respiratory samples and collected epidemiological and clinical data. IS compiled and analysed the clinical data. LJ performed the statistical analyses. AM performed the phylogenetic analyses. IS, AM and LJ wrote the first draft of the paper. All the authors, including $\mathrm{BL}, \mathrm{CH}, \mathrm{DA}$ and $\mathrm{HPL}$, reviewed the manuscript critically.

\section{References}

1. Imamura T, Oshitani H. Global reemergence of enterovirus D68 as an important pathogen for acute respiratory infections. Rev Med Virol. 2015;25(2):102-14. DOI: 10.1002/rmv.1820 PMID: 25471236

2. Khetsuriani N, Lamonte-Fowlkes A, Oberst S, Pallansch MA, Centers for Disease Control and Prevention. Enterovirus surveillance--United States, 1970-2005.MMWR Surveill Summ. 2006;55(8):1-20.PMID: 16971890

3. Ikeda T, Mizuta K, Abiko C, Aoki Y, Itagaki T, Katsushima F, et al. Acute respiratory infections due to enterovirus 68 in Yamagata, Japan between 2005 and 2010. Microbiol Immunol. 2012;56(2):139-43. DOI: 10.1111/j.1348-0421.2012.00411.x PMID: 22309616

4. Imamura T, Fuji N, Suzuki A, Tamaki R, Saito M, Aniceto $R$, et al. Enterovirus 68 among children with severe acute respiratory infection, the Philippines. Emerg Infect Dis. 2011;17(8):1430-5. DOI: 10.3201/eid1708.101328 PMID: 21801620

5. Tokarz R, Kapoor V, Wu W, Lurio J, Jain K, Mostashari F, et al. Longitudinal molecular microbial analysis of influenza-like illness in New York City, May 2009 through May 2010. Virol J. 2011;8(1):288. DOI: 10.1186/1743-422X-8-288 PMID: 21658237

6. Rahamat-Langendoen J, Riezebos-Brilman A, Borger R, van der Heide R, Brandenburg A, Schölvinck E, et al. Upsurge of human enterovirus 68 infections in patients with severe respiratory tract infections. J Clin Virol. 2011;52(2):103-6. DOI: 10.1016/j.jcv.2011.06.019 PMID: 21802981

7. Meijer A, van der Sanden S, Snijders BE, Jaramillo-Gutierrez $G$, Bont L, van der Ent CK, et al. Emergence and epidemic occurrence of enterovirus 68 respiratory infections in The Netherlands in 2010. Virology. 2012;423(1):49-57. DOI: 10.1016/j.virol.2011.11.021 PMID: 22177700

8. Petitjean-Lecherbonnier J, Dina J, Nguyen E, Gouarin S, Lebigot E, Vabret A. [Molecular diagnosis of respiratory enterovirus infections: Use of PCR and molecular identification for a best approach of the main circulating strains during 2008]. Pathol Biol (Paris). 2011;59(2):113-21. DOI: 10.1016/j. patbio.2010.07.010 PMID: 20828940

9. Renois F, Bouin A, Andreoletti L. Enterovirus 68 in pediatric patients hospitalized for acute airway diseases.J Clin Microbiol. 2013;51(2):640-3. DOI: 10.1128/JCM.02640-12 PMID: 23224095

10. Piralla A, Girello A, Grignani M, Gozalo-Margüello M, Marchi A, Marseglia G, et al. Phylogenetic characterization of enterovirus 68 strains in patients with respiratory syndromes in Italy. J Med Virol. 2014;86(9):1590-3. DOI: 10.1002/ jmv.23821 PMID: 24155220

11. Lauinger IL, Bible JM, Halligan EP, Aarons EJ, MacMahon E, Tong CYW. Lineages, sub-lineages and variants of enterovirus 68 in recent outbreaks.PLoS One. 2012;7(4):e36005. DOI: 10.1371/journal.pone.0036005 PMID: 22536453

12. Greninger AL, Naccache SN, Messacar K, Clayton A, Yu G, Somasekar S, et al. A novel outbreak enterovirus D68 strain associated with acute flaccid myelitis cases in the USA (2012-14): a retrospective cohort study. Lancet Infect Dis. 2015;15(6):671-82. DOI: 10.1016/S1473-3099(15)70093-9 PMID: 25837569

13. Midgley CM, Jackson MA, Selvarangan R, Turabelidze G, Obringer E, Johnson D, et al. Severe respiratory illness associated with enterovirus D68 - Missouri and Illinois, 2014. MMWR Morb Mortal Wkly Rep. 2014;63(36):798-9.PMID: 25211545

14. Oermann CM, Schuster JE, Conners GP, Newland JG, Selvarangan R, Jackson MA. Enterovirus d68. A focused review and clinical highlights from the US outbreak. Ann Am Thorac Soc. 2015;12(5):775-81. DOI: 10.1513/AnnalsATS.201412-592FR PMID: 25714788

None declared. 
15. European Centre for Disease Prevention and Control (ECDC). Enterovirus 68 detected in the USA, Canada and Europe Second update 24 November 2014. Stockholm: ECDC; 2014

16. Bragstad K, Jakobsen K, Rojahn AE, Skram MK, Vainio K, Holberg-Petersen $M$, et al. High frequency of enterovirus D68 in children hospitalised with respiratory illness in Norway, autumn 2014. Influenza Other Respi Viruses. 2015;9(2):59-63. DOI: 10.1111 /irv.12300 PMID: 25534826

17. Poelman R, Schölvinck EH, Borger R, Niesters HGM, van Leer-Buter C. The emergence of enterovirus D68 in a Dutch University Medical Center and the necessity for routinely screening for respiratory viruses.J Clin Virol. 2015;62:1-5. DOI: 10.1016/j.jcv.2014.11.011 PMID: 25542461

18. Antona D, Lévêque N, Chomel JJ, Dubrou S, Lévy-Bruhl D, Lina B. Surveillance of enteroviruses in France, 2000-2004.Eur J Clin Microbiol Infect Dis. 2007;26(6):403-12. DOI: 10.1007/s10096007-0306-4 PMID: 17534678

19. Lang M, Mirand A, Savy N, Henquell C, Maridet S, Perignon R, et al. Acute flaccid paralysis following enterovirus D68 associated pneumonia, France, 2014. Euro Surveill. 2014;19(44):20952. DOI: 10.2807/1560-7917. ES2014.19.44.20952 PMID: 25394254

20. Poelman R, Schuffenecker I, Van Leer-Buter C, Josset L, Niesters HGM, Lina B, ESCV-ECDC EV-D68 study group. European surveillance for enterovirus D68 during the emerging North-American outbreak in 2014.J Clin Virol. 2015;71:1-9. DOI: 10.1016/j.jcv.2015.07.296 PMID: 26364237

21. Savolainen C, Mulders MN, Hovi T. Phylogenetic analysis of rhinovirus isolates collected during successive epidemic seasons.Virus Res. 2002;85(1):41-6. DOI: 10.1016/S01681702(02)00016-3 PMID: 11955637

22. Nix WA, Oberste MS, Pallansch MA. Sensitive, seminested PCR amplification of VP1 sequences for direct identification of all enterovirus serotypes from original clinical specimens.) Clin Microbiol. 2006;44(8):2698-704. DOI: 10.1128/JCM.00542-06 PMID: 16891480

23. Linsuwanon P, Payungporn S, Samransamruajkit R, Posuwan N, Makkoch J, Theanboonlers A, et al. High prevalence of human rhinovirus $C$ infection in Thai children with acute lower respiratory tract disease. J Infect. 2009;59(2):115-21. DOI: 10.1016/j.jinf.2009.05.009 PMID: 19556008

24. Drummond AJ, Rambaut A. BEAST: Bayesian evolutionary analysis by sampling trees.BMC Evol Biol. 2007;7(1):214. DOI: 10.1186/1471-2148-7-214 PMID: 17996036

25. Refabert L. Management of bronchiolitis. Proceedings of the French consensus conference; 2000 Sep 21; Paris, France. French. Available from http://www.has-sante.fr/portail/ upload/docs/application/pdf/bronchio.pdf

26. Marguet C, Groupe de Recherche Sur Les Avancées En PneumoPédiatrie. [Management of exacerbated asthma in children].Rev Mal Respir. 2007;24:427-39. DOI: 10.1016/So7618425(07)91567-3 PMID: 17468701

27. Tokarz R, Firth C, Madhi SA, Howie SRC, Wu W, Sall AA, et al. Worldwide emergence of multiple clades of enterovirus 68. J Gen Virol. 2012;93(Pt 9):1952-8. DOI: 10.1099/vir.0.043935-0 PMID: 22694903

28. Imamura T, Suzuki A, Lupisan S, Okamoto M, Aniceto R, Egos RJ, et al. Molecular evolution of enterovirus 68 detected in the Philippines. PLoS One. 2013;8(9):e74221. DOI: 10.1371/journal. pone.0074221 PMID: 24073203

29. Mosnier A, Caini S, Daviaud I, Bensoussan JL, Stoll-Keller F, Bui TT, et al., GROG network. Ten influenza seasons in France: distribution and timing of influenza $A$ and $B$ circulation, 20032013. BMC Infect Dis. 2015;15(1):357. DOI: 10.1186/s12879-0151056-z PMID: 26289794

30. Casalegno JS, Ottmann M, Bouscambert-Duchamp M, Valette $M$, Morfin F, Lina B. Impact of the 2009 influenza $A\left(\mathrm{H}_{1} \mathrm{~N}_{1}\right)$ pandemic wave on the pattern of hibernal respiratory virus epidemics, France, 2009.Euro Surveill. 2010;15(6):19485.PMID: 20158981

31. Drews SJ, Simmonds K, Usman HR, Yee K, Fathima S, Tipples G, et al. Characterization of enterovirus activity, including that of enterovirus D68, in pediatric patients in Alberta, Canada, in 2014. J Clin Microbiol. 2015;53(3):1042-5. DOI: 10.1128/ JCM.02982-14 PMID: 25588657

32. Cordey S, Petty TJ, Schibler M, Martinez Y, Gerlach D, van Belle $S$, et al. Identification of site-specific adaptations conferring increased neural cell tropism during human enterovirus 71 infection. PLoS Pathog. 2012;8(7):e1002826. DOI: 10.1371/ journal.ppat.1002826 PMID: 22910880

33. Vignuzzi M, Stone JK, Arnold JJ, Cameron CE, Andino R. Quasispecies diversity determines pathogenesis through cooperative interactions in a viral population. Nature. 2006;439(7074):344-8. DOI: 10.1038/nature04388 PMID: 16327776
34. Bal A, Schuffenecker I, Casalegno JS, Josset L, Valette M, Armand N, et al. Enterovirus D68 nosocomial outbreak in elderly people, France, 2014. Clin Microbiol Infect. 2015;21(8):e61-2. DOI: 10.1016/j.cmi.2015.05.008 PMID: 25986875

35. Huang S-W, Hsu Y-W, Smith DJ, Kiang D, Tsai H-P, Lin K-H, et al. Reemergence of enterovirus 71 in 2008 in taiwan: dynamics of genetic and antigenic evolution from 1998 to 2008. J Clin Microbiol. 2009;47(11):3653-62. DOI: 10.1128/JCM.00630-09 PMID: 19776232

36. Hassel C, Mirand A, Lukashev A, TerletskaiaLadwig E, Farkas A, Schuffenecker I, et al. Transmission patterns of human enterovirus 71 to, from and among European countries, 2003 to 2013 . Euro Surveill. 2015;20(34):30005. DOI: $10.2807 / 1560-$ 7917.ES.2015.20.34.30005 PMID: 26530407

37. Imamura T, Okamoto M, Nakakita S, Suzuki A, Saito M, Tamaki R, et al. Antigenic and receptor binding properties of enterovirus 68. J Virol. 2014;88(5):2374-84. DOI: 10.1128 / JVI.03070-13 PMID: 24371050

38. Jacobs SE, Lamson DM, St George K, Walsh TJ. Human rhinoviruses.Clin Microbiol Rev. 2013;26(1):135-62. DOI: 10.1128/CMR.00077-12 PMID: 23297263

\section{License and copyright}

This is an open-access article distributed under the terms of the Creative Commons Attribution (CC BY 4.0) Licence. You may share and adapt the material, but must give appropriate credit to the source, provide a link to the licence, and indicate if changes were made.

This article is copyright of the authors, 2016. 